\title{
THE NSIS STUDENT SCIENCE WRITING COMPETITION
}

\author{
HANK M.B. BIRD* \\ NSIS - SSWC Coordinator \\ 15 Amber Drive, Williamswood, NS B3V 1 E8
}

\section{ORIGINS AND CRITERIA}

The annual Student Science Writing Competition (SSWC) started in 2003 as a vehicle for encouraging science and engineering students to practice and improve their writing skills. It has been open to any student registered at a Nova Scotian university or college.

As stated in the original announcements, the competition was designed to encourage and reward students for their skills in the communication of science. In 2003 prizes were awarded to undergraduates $(\$ 250)$ and postgraduates $(\$ 500)$, and three general categories were acknowledged:

- A concise discussion of original research.

- A review of current literature in a scientific field that provides a new analysis or perspective.

- An article directed to a non-specialist audience on some aspect of science and its impact on society.

At the same time a prize was awarded to students in programs such as journalism, history of science, or public relations for an article about the practice of science, or how it impacts on society.

In certain circumstances, a second prize or an Honourable Mention could also be awarded. Importantly, all winners are invited to submit their manuscripts to the PNSIS for consideration as a primary publication.

\section{EVOLUTION OF THE COMPETITION}

Over the years, as student submissions have accumulated, the SSWC has evolved in terms of emphasis. There is no longer a separate prize for students in journalism, etc., although such students, 
as undergraduates or postgraduates, are still eligible to submit manuscripts.

As well, the need for good communication of science to nonspecialists has become more important for society as a whole. First, NSIS members come from a wide range of scientific disciplines or are members of the general public with an interest in science, and they appreciate articles outside their discipline that are interesting and comprehensible. Second, science needs to be more clearly communicated to the public at large and to decision-makers in academe, business, government and the military. When students become practitioners of science, they need to be able to impart their knowledge and results to non-specialists. As a result, judges now give more emphasis to this criterion when evaluating all submissions.

In recent years, the prizes have been increased to $\$ 500$ (undergraduate winner) and $\$ 750$ (postgraduate winner). Also, all students who submit a manuscript are now offered a free 1-year Student NSIS Membership.

\section{THE SSWC PROCESS}

Originally, the process was conducted on paper and by telephone. Since computer tools and communications became more useful and widespread, the SSWC is conducted today almost entirely by digital means.

For the competition for a given year, the process starts in about late October of the previous year. An announcement is e-mailed out to all science and engineering deans and department chairs at all Nova Scotian universities and colleges, and to their administrative assistants, asking them to publicize the SSWC to their faculty and students. Announcements are also sent to the presidents of all science and engineering student societies. The SSWC is also posted on social media at some of the universities, and posters are placed in a number of strategic locations. Reminders are sent in early December to the above recipients. Paid advertisements are also put up on social media for several weeks in late December and early January.

The announcements ask the students to register by the end of January, and to submit their manuscripts to the Coordinator by the middle of February. Students who register are sent an "Information for Authors" document which describes the requirements and offers 
some advice for the preparation of manuscripts. Students who register are asked for a short paragraph describing their motivation for selecting the topic of their proposed paper (essay or article). Also, they are sent a reminder of the deadline in early February.

By the submission deadline, the Coordinator assembles a panel of five to eight judges. All are NSIS members, and many are drawn from current or former members of the NSIS Council. The judges are chosen to ensure coverage of a range of disciplines.

Once the papers have been submitted, the Coordinator sends copies of all of them to each of the judges, with students' names and academic affiliation removed. The judges return their individual evaluations to the Coordinator by mid-March, who compiles them and sends the compilation back to all the judges.

The judges meet in late March, discuss the papers, and arrive at the final decisions. There can be a Winner and/or an Honourable Mention in each of the undergraduate and the postgraduate categories, but this does not always occur. Sometimes, no prize is given in a category for the Winner or the Honourable Mention. In addition to the results, the judges discuss the constructive feedback that will be given by the Coordinator to each student who submitted a paper.

At the beginning of the April NSIS Public lecture, we give the prizes in person to those students who can attend. Otherwise, the cheques and certificates are mailed to the other Winners and to the Honourable Mentions.

\section{COMMENTS AND OBSERVATIONS}

Each year, the SSWC attracts a variable number of students who register their intent to participate, of which a fraction eventually submits manuscripts for consideration. Figure 1 shows these numbers for the past twelve years. The main reason for students dropping out of the competition is usually the pressure of other academic obligations.

The surge in numbers in 2014 is attributed to having a more thorough publicity of the SSWC across all university and college departments. The jump in 2016 coincided with the increased size of the cash prizes.

Over the years, virtually all Nova Scotian universities and colleges have provided competitors and most have provided one or 


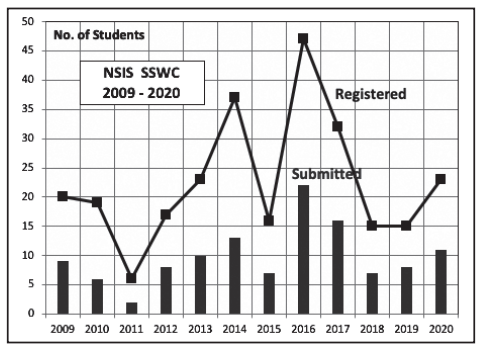

Fig 1 Numbers of interested students and submitted articles, 2009 to 2020.

more winners. Nevertheless, most of the competitors (about twothirds) have been from Dalhousie University, it being the institution with the largest science and engineering components. The NSIS will keep trying to increase participation from the other universities and colleges in the province.

The papers that students submit cover a very wide range of disciplines and topics. There tends to be a focus on biological and ecological topics, but chemistry, geology, agriculture, ocean science, physics and engineering, and medicine are often represented. About half the papers are descriptions of some original research; the rest are reviews of scientific matters of current importance. The manuscripts are nearly always interesting, informative and well-written. Many are a true delight to read.

Each year, the judges consider and make recommendations for improvements in the SSWC. The result has been steady small changes in procedures, criteria, ways to publicize the competition, advice given to contestants, and the judging process itself.

We still struggle a little with making sure the students clearly understand that their submissions (essays or articles) should be accessible to non-specialists - people with an interest in science but without expertise in the particular topic or field of science. For example, the magazine "Scientific American" is a good role model. We still receive a few papers that are of refereed, journalgrade quality but which are opaque to all but an expert. However, these sometimes win the competition and are published in the PNSIS!

A personal comment - I have been the NSIS SSWC Coordinator since 2013 and have enjoyed the experience very much. The best part has been the pleasure of reading and assessing all of the submissions 
prepared by keen students covering diverse topics. For the upcoming 2021 SSWC, I am passing on the role to a pair of Co-Coordinators; I am confident that they will bring new ideas and improvements to the SSWC, a core part of the annual NSIS program. 
